\title{
Gallbladder carcinosarcoma
}

\author{
Jeffrey J Pu, ${ }^{1}$ Weize $\mathrm{Wu}^{2}$ \\ 1The Sidney Kimmel Comprehensive Cancer Center, Johns Hopkins Medicine, Baltimore, Maryland, USA; \\ 2Department of Surgery, Ruijin Hospital, Shanghai Jiaotong University School of Medicine, Shanghai, China
}

Correspondence to Jeffrey J Pu, JPU2@jhmi.edu

\begin{abstract}
Summary
Gallbladder carcinosarcoma is a rare gastrointestinal tract malignant tumour, which contains both epithelial cancer component and mesenchymal sarcoma component. Because of its unique anatomic location and unspecific medical presentation, preoperative diagnosis is difficult. The prognosis of gallbladder carcinoma is poor with median survival time of 5.5 months. T- and $\mathrm{N}$-staging system has no role in cancer prognostic stratification. Currently, we still have limited experience in managing this form of notorious cancer. Surgical resection is the common practice in treating gallbladder carcinoma though recurrence rate is high (80\%). Here, we report a 59-year-old female with new diagnosed gallbladder carcinosarcoma. She was found to have a carcinosarcoma masse at gallbladder extending into proximal bile ducts with no metastatic lesion. She underwent a radical cholangiocholecystocholedochectomy and Roux-en-Y hepatocholangioduodenostomy. Postsurgery, she received six cycles of adjuvant chemotherapy consisting of oxaliplatin and 5-fluorouracil. She maintains in complete remission 6 months after adjuvant chemotherapy.
\end{abstract}

\section{BACKGROUND}

Gallbladder carcinosarcoma is one of extremely rare cancers, which only makes up $4.1 \%$ of gallbladder cancer. Because of its unique anatomical location, the physical presentations of gallbladder carcinosarcoma are usually not specific. Like other biliary tract diseases, gallbladder carcinosarcoma is often associated with cholecystolithiasis. The final diagnosis of carcinosarcoma requires thorough surgical pathology studies, which includes immunohistological staining. Our experience to manage gallbladder carcinosarcoma is still limited so far. In this case report, for the first time we report a patient with gallbladder carcinosarcoma who received both radical surgical resection and adjuvant chemotherapy. The patient remains in complete remission 6 month after finishing her chemotherapy.

\section{CASE PRESENTATION}

A 59-year-old female presented to her primary physician with a worsening right upper quadrant abdominal dull pain for about 2 months, which radiated to her shoulders and back. She started to experience fever $\left(38.6^{\circ} \mathrm{C}\right)$, intermittent chilling attack associated with nausea and mild vomiting in last 2 days. She did not have obvious weight loss or appetite change. Her medical history was no significant, except for one episode of right upper quadrant abdominal pain 10 years ago that was diagnosed as cholecystolithiasis via abdominal ultrasound. She was managed with non-surgical treatments at that time and there were no similar attacks afterwards. On physical examination, she was found to have conjunctival icterus and skin non-pruritic jaundice. Whole abdomen was soft with mild deep tenderness at right upper quadrant, no rebounding. Her urine appeared as dark tea-coloured. Laboratory blood tests showed white blood cells of $7.9 \times 10^{9} / 1$, haemoglobin of $134 \mathrm{~g} / \mathrm{l}$, platelet of $299 \times 10^{9} / 1$, alanine aminotransferase of $131 \mathrm{IU} / 1$, alkaline phosphatase of $746 \mathrm{IU} / 1, \gamma$-glutamyl transpeptidase of $1484 \mathrm{IU} / \mathrm{l}$, total bilirubin of $274 \mathrm{mmol} / \mathrm{l}$, direct bilirubin of $159 \mathrm{mmol} / \mathrm{l}$ and serum albumin of $28 \mathrm{~g} / \mathrm{l}$. Her serum cancer antigen 19.9 (CA19.9) was elevated to $12000 \mathrm{U} / \mathrm{ml}$, but her carcinoembryonic antigen (CEA) and $\alpha$-fetoprotein $(\alpha \mathrm{FP})$ values were at normal ranges.

\section{INVESTIGATIONS}

This patient was immediately sent for imaging studies. The ' $\mathrm{B}$ '-ultrasound showed a swollen gallbladder measuring $146 \times 40 \mathrm{~mm}^{2}$ with a wall thickness of $2 \mathrm{~mm}$. Within the gallbladder, there were many gallstones together with a space-occupying mass, which showed irregular and uneven echogenicity. The largest gallstone was $14 \times 9 \mathrm{~mm}^{2}$ in size. The gallbladder mass did not move along with patient's posture change (figure 1). The inner diameter of the common bile duct was $22 \mathrm{~mm}$. It was filled up with punctuated isotropic echoing substances. The intrahepatic ducts showed widespread dilation, measuring $5-7 \mathrm{~mm}$ in diameter. The abdomen CT with contrast showed gallbladder mass intermingled with gallbladder stones, enlarged hilar lymph nodes, dilated intrahepatic ducts and multiple liver cysts (figure 2). However, chest CT and pelvis CT did not show any additional mass lesion. Then, an endoscopic retrograde cholangiopancreatography was performed, which showed that the common bile duct was $20 \mathrm{~mm}$ in diameter. Within it, there was a $15 \times 5 \mathrm{~mm}^{2}$ filling defect extending from hepatic hilum to the middle of common bile duct. The intrahepatic ducts were dilated and the gallbladder was partially shown. The inserted T-tube drained out blood-stained bile (figure 3 ).

The clinical diagnosis showed hepatobiliary tract infection, obstructive jaundice, common bile duct stone and gallbladder cancer. An exploratory laparotomy was performed. The intraoperative findings showed a swollen gallbladder with high tension. The serosal surface of the gallbladder was smooth and intact. The cystic duct was 


\section{BMJ Case Reports}

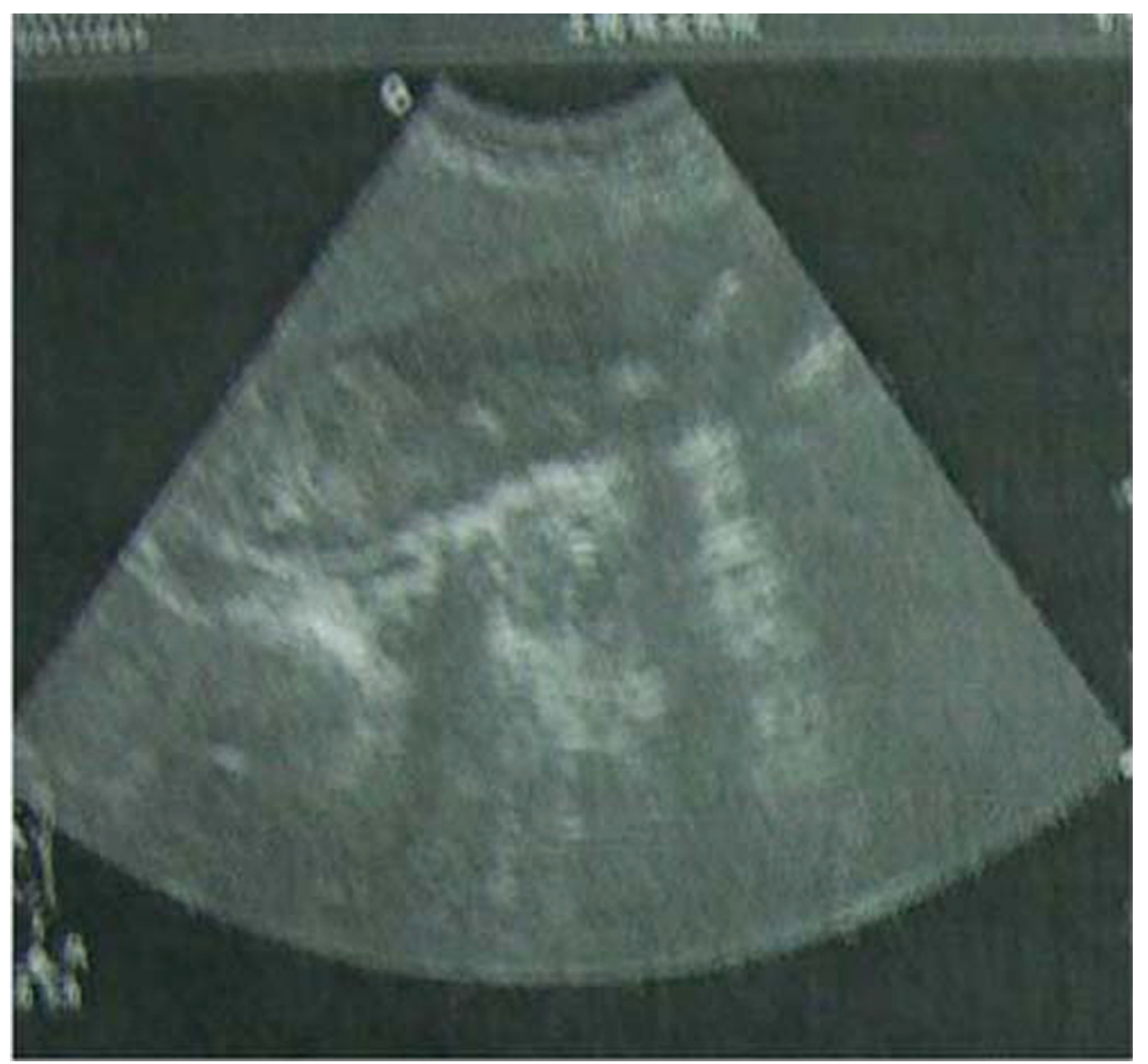

Figure 1 The ultrasound of gallbladder.

thickened measuring $10 \mathrm{~mm}$ in diameter. The common bile duct was about $20 \mathrm{~mm}$ in diameter with increased tension. There were soft masses in the gallbladder and common bile duct. After cutting open the gallbladder, a $60 \times 30$ $\mathrm{mm}^{2}$ necrotic tumour mass was found attached with gallbladder wall. This tumour mass appeared necrotic, mixed with gallbladder stones and blood clots. This mass compressed on cystic duct neck and extended into cystic ducts, upper and middle sections of common bile duct. Intraoperation cholangiography showed no mass in distal common bile duct and intrahepatic ducts. Whole gallbladder along with proximal and middle segments of common bile duct were resected. Radical lymph node resection was performed, which involved hepatic hilum and portal tract region lymph nodes. The frozen resection samples from distal common bile duct dissection margins showed no tumour cells. Finally, the distal common bile duct was closed and a hepatocholangojejunostomy Roux-en-Y was performed.

\section{Surgical pathology results}

In gross view, the gallbladder was $120 \times 25 \times 6 \mathrm{~mm}^{3}$ in size covered with grey-whitish and focally grey-reddish mucosa. The gallbladder wall was $2-4 \mathrm{~mm}$ thick. Near cystic duct, there was a polypoid tumour of $10 \times 8 \mathrm{~mm}^{2}$ in size, just $5 \mathrm{~mm}$ above the mucosal surface. The tumour mass within the gallbladder measured $110 \times 25 \times 22 \mathrm{~mm}^{3}$ in size. It had solid grey-whitish/brownish cut surface with focal cystic change and significant calcification. The tumour mass was soft and fleshy with some haemorrhage and necrosis (figure 4). The sloughing gallbladder tumour drained through dilated cystic duct to common bile duct causing emboli-induced bile duct obstruction.

In microscopic view, the tumours showed dual differentiation with malignant columnar cells forming glands and sarcomatous spindle cells arranging in fascicles and whorls interspersing among them. There was no transition between the malignant epithelial and sarcomatous components. The sarcomatous tumour cells were highly pleomorphic. Tumour giant cells were frequently seen at mitotic phase (figure $5 \mathrm{~A}, \mathrm{~B}$ ).

In immunohistochemical studies, the epithelial component was positive for $\mathrm{AE} 1+/ \mathrm{AE} 3+, \mathrm{CEA}+, \mathrm{EMA}+, \mathrm{P} 53+++$ (figure $6 \mathrm{~A}$ ) and the sarcomatous component expressed vimentin+ (figure 6B).

These results confirmed the diagnosis of gallbladder carcinosarcoma.

There were no tumour cells found in eight lymph nodes removed from hepatic hilum and portal tract regions. The proximal common bile duct resection margin was clean. Thus, this gallbladder carcinoma was classified as stage II (T1bN0M0).

\section{TREATMENT}

Twenty days postsurgery, this patient started to receive adjuvant chemotherapy, which consisted of oxaliplatin 


\section{BMJ Case Reports}

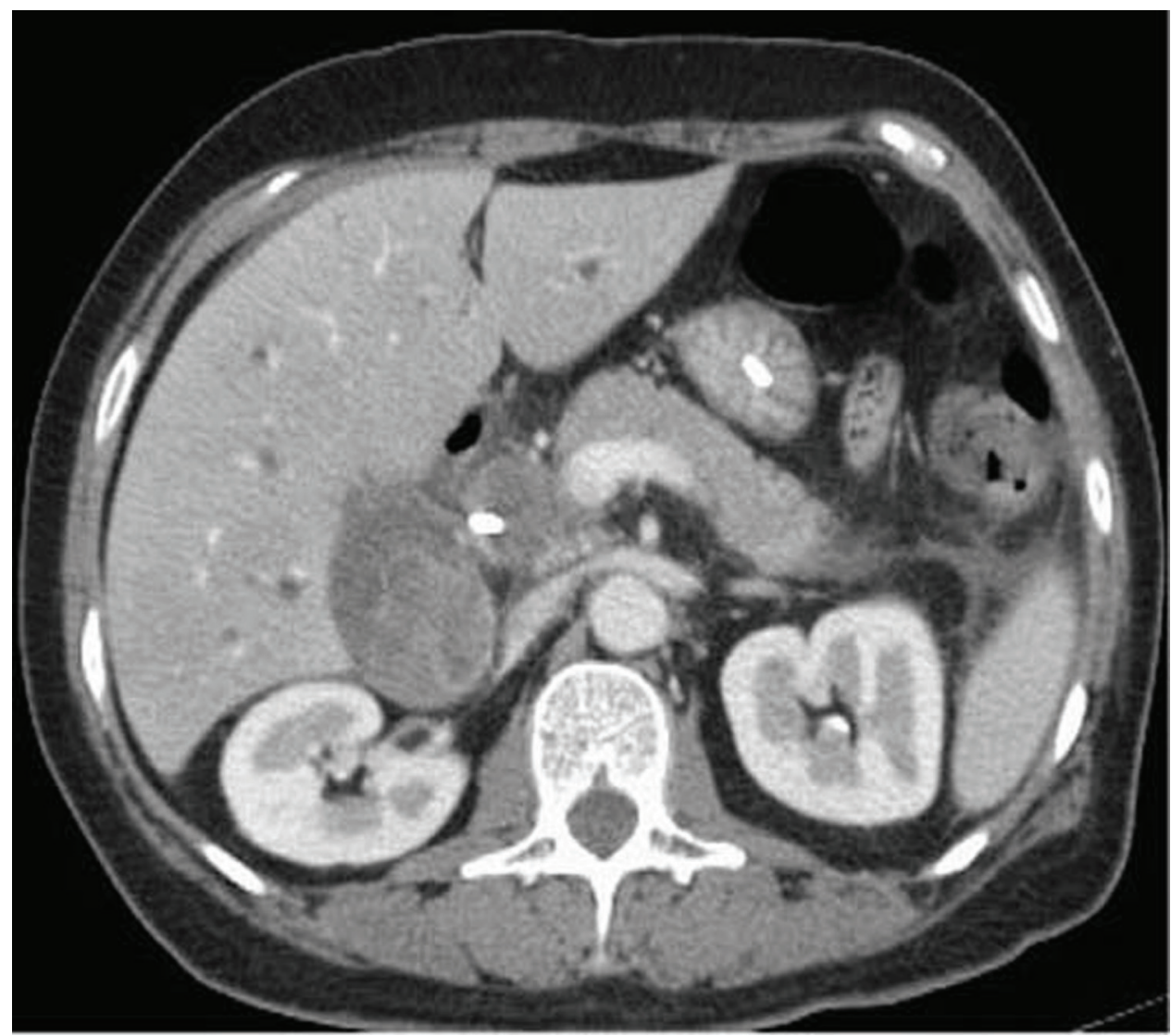

Figure 2 Abdominal CT scan.

$150 \mathrm{mg}$ and 5-fluorouracil (5-Fu) $500 \mathrm{mg}$ intravenously every 30 days, totally six cycles.

\section{OUTCOME AND FOLLOW-UP}

She recovered well after all. On a 6-month follow-up, her abdominal CT did not show any mass or enlarged lymph nodes. Her serum CA19.9 level dropped down to normal level at $35 \mathrm{U} / \mathrm{ml}$ and CEA, CA125, $\alpha$ FP levels remain at normal ranges.

\section{DISCUSSION}

The most common histological type of gallbladder cancer is adenocarcinoma. ${ }^{1-5}$ The gallbladder carcinosarcoma is extremely rare in clinical practice. ${ }^{67}$ Since Landsteiner et a ${ }^{8}$ published first case of gallbladder carcinosarcoma in 1907, there have been only about 50 cases reported in the world literature. ${ }^{1}$ 9-12 Because carcinosarcoma contains both malignant epithelial and sarcomatous components, immunohistochemical study appears as an inevitable methodology in differential diagnosis. Diagnosis of carcinosarcoma requires the presence of both components in tissue with various combination and proportion. ${ }^{13}$ Carcinosarcoma could occur at almost all major organs, such as lung, kidney, upper aerodigestive tract, salivary gland, thyroid, thymus and gastrointestinal tract. ${ }^{16}$ However, the most common site for carcinosarcoma is the uterus, where the tumour is better known as malignant mixed mullerian tumour. ${ }^{14}$ The gallbladder carcinosarcoma is more common in females with a female to male ratio of $2: 1$ to $5: 1 .^{2} 11$ The average age range of cancer occurrence is $60-70$ years old. ${ }^{2}$ The disease progress of this neoplasm is extremely aggressive. The median survival time is 5.5 months and the longest postsurgery survival time was 60 months. ${ }^{6} 9111215-16$ In a cohort study of 26 gallbladder carcinosarcoma cases, only 3 cases had survival time over 12 months. ${ }^{1}$

$\mathrm{T}$ - and $\mathrm{N}$-staging system proved to be a valuable tool in gallbladder carcinoma prognostic factor stratification. ${ }^{17} 18$ However, this system has no role in gallbladder carcinosarcoma prognosis stratification. Liu et al and other groups analysed 48 patients in stages II to IV and demonstrated that the mean survival time was about 2 months regardless of their tumour stage status. ${ }^{11} 1920$

Patients with gallbladder carcinosarcoma often present with vague abdominal symptoms, such as dull abdominal pain, nausea, jaundice and weight loss. Occasionally, there is a palpable right upper quadrant mass. About $74 \%$ of the gallbladder carcinosarcoma cases are associated with cholecystolithiasis and ultrasounds often show a polypoid mass. Serum CA19.9 level also may be elevated. CT scan can not distinguish gallbladder carcinosarcoma from adenocarcinoma. However, gallbladder carcinosarcoma should be highly suspected if there is speckled calcification within the tumour. ${ }^{21-23}$ In our case, this patient presented with worsening biliary tract obstruction symptoms associated with a secondary infection. Intraoperative observation demonstrated a sloughing gallbladder tumour mass mixed with calcified gall stones and compressed gallbladder neck, which facilitated tumour emboli formation and obstructed cystic ducts. Because tumour embolus is a rare cause for bile 


\section{BMJ Case Reports}

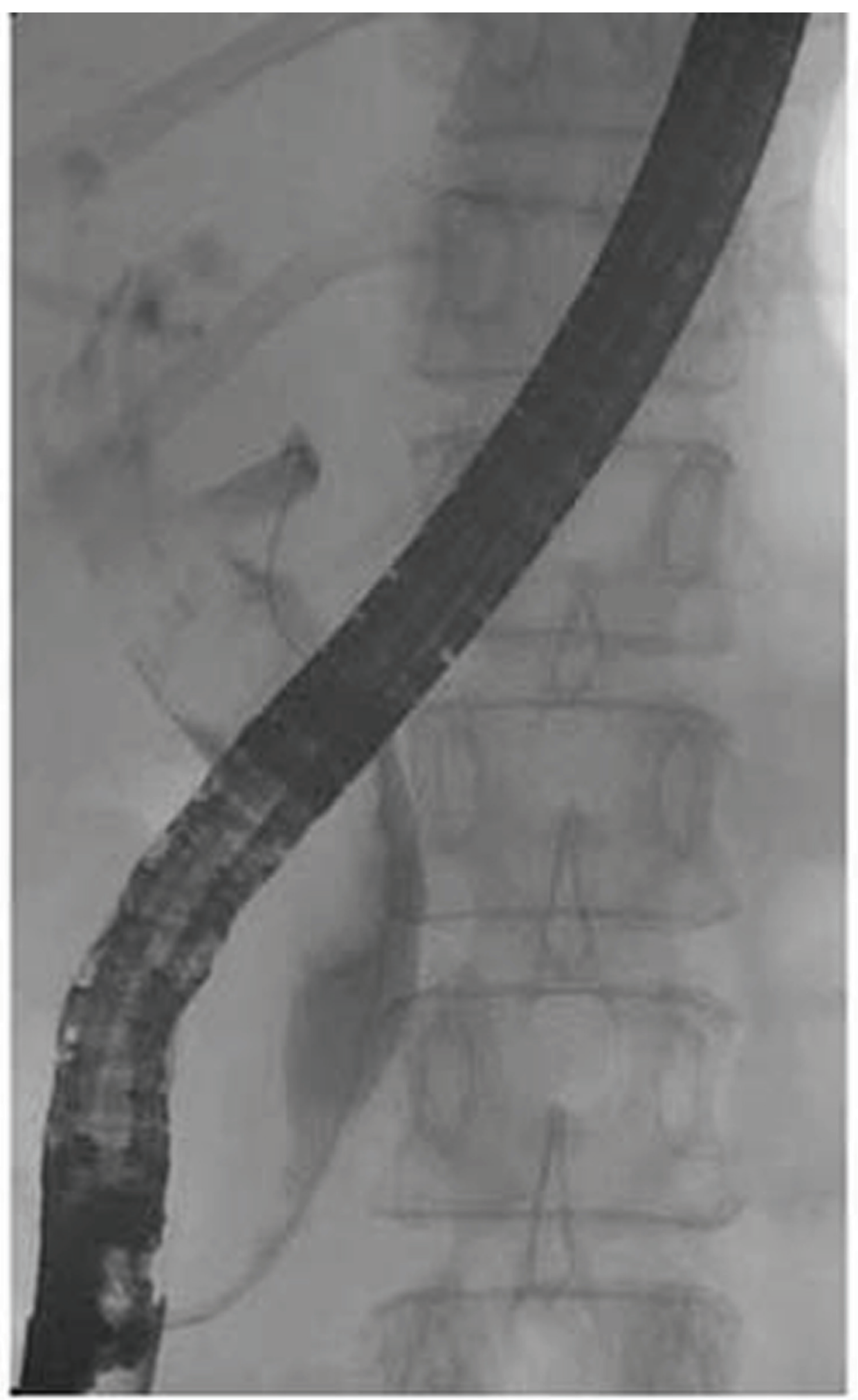

\section{Figure 3 ERCP exam.}

duct obstruction, we report our observation here to raise proper clinical attention.

Gallbladder carcinosarcoma has dual histological differentiations, which include both epithelial and sarcomatous elements. The sarcoma mesenchymal stromal differentiation is an important characteristic evidence for diagnosis of carcinosarcoma. Because sarcomatoid cells express both epithelial membrane antigen and cytokeratin markers, they are considered deriving from mesenchyme of carcinoma cells. $^{24} 25$ The sarcomatous element simply shows nonspecific spindle cell morphology. ${ }^{1}$ But sometimes, more specific mesenchymal differentiation, which is known 


\section{BMJ Case Reports}

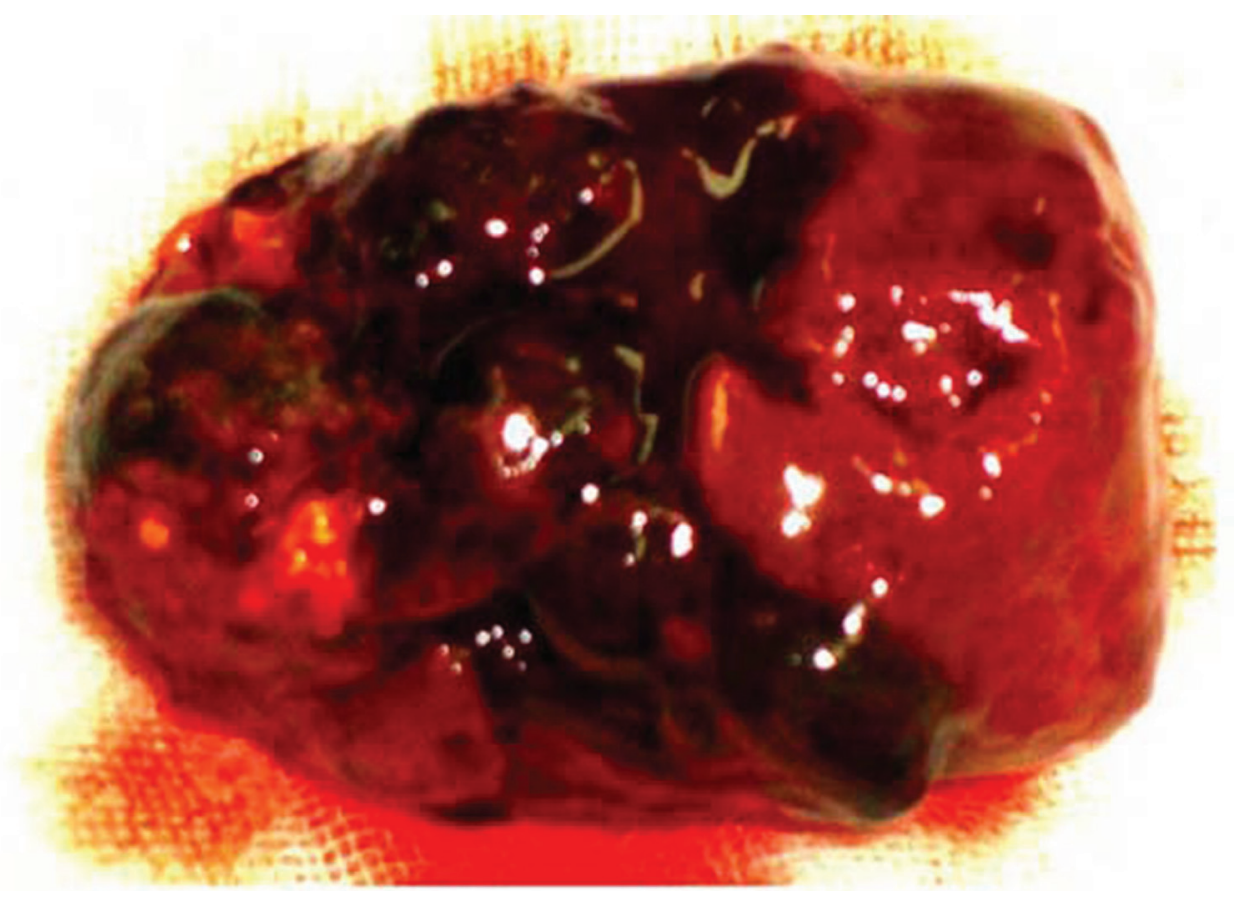

Figure 4 Tumour gross pathology view.
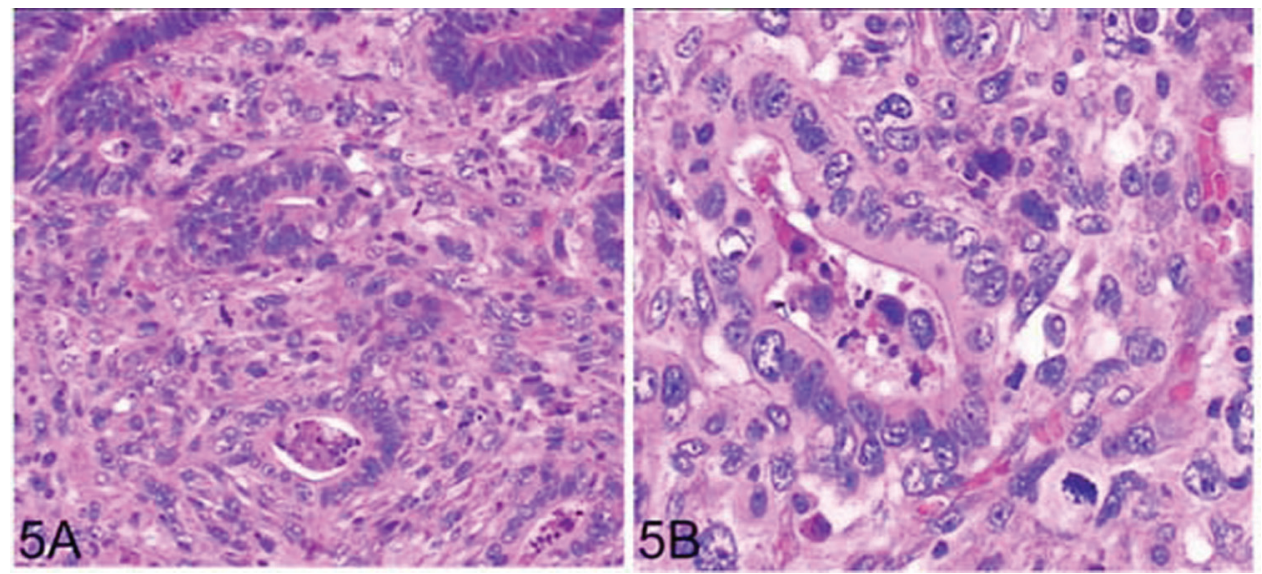

Figure 5 The tumour showed dual differentiation with malignant columnar glandular cells and sarcomatous spindle cells $(A$ : HE $\times 40$; B: HE $\times 100)$.

as heterogenous elements, can be recognised in certain carcinosarcomas, such as leiomyosarcoma, rhabdomyosarcoma, osteosarcoma and chondrosarcoma. Biologic behaviour of carcinosarcoma is similar to that of advanced sarcoma. Majority of cases manifested as tumour rapid growth and compression to surrounding organs. Exact tumorigenesis mechanism of gallbladder carcinosarcoma is still unknown. One study indicated that certain genetic and gene expression alterations may be relevant to the sarcomatous change/epithelial mesenchymal transition in cholangiocarcinoma cells. ${ }^{26}$ Another report further linked K-Ras alterations with disrupted cell cycle regulation and gallbladder carcinogenesis. ${ }^{27}$

Currently, we have very limited experience in managing patients with gallbladder carcinosarcoma. Because of the rarity of this disease, it is impossible to conduct a clinical trial to investigate various therapeutic options at this time. Patients usually receive surgical managements. In general, patients with stage I tumour usually receive cholecystectomy, whereas advanced tumour requires cholecystectomy plus radical regional lymph node excision. If the tumour is limited within submucosa, simple cholecystectomy will be the treatment choice. ${ }^{1} 1112$ When tumour is limited within gallbladder, cholecystectomy with excision of liver tissue surrounding gallbladder bed will be sufficient. Similar to other gallbladder tumours, advanced-stage gallbladder carcinosarcoma is often impossible to have a complete excision. Debulking resection can be used for symptom relieving in palliative surgery. Extensive excision of surrounding liver tissue or right hemi-hepatectomy increases only its negative margin but not patient's survival. Furthermore, radical surgical resection brings more surgery-related risks. Patients with early-stage gallbladder carcinosarcoma may have survival benefit from radical 


\section{BMJ Case Reports}

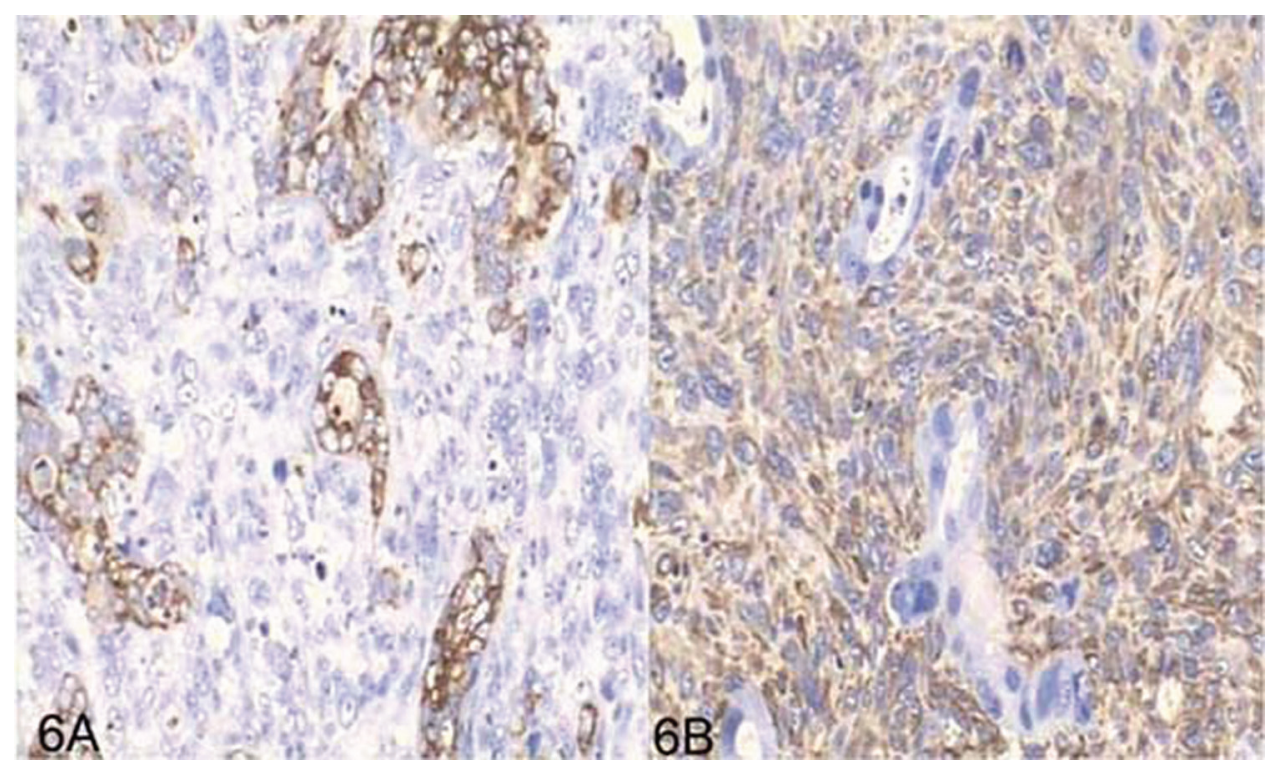

Figure 6 Special immunohistostainings show the epithelial component $(A, \times 100)$ positive on anti-AE1 $+/ A E 3+$ staining, and the sarcomatous component $(B, \times 40)$ positive on anti-vimentin staining.

cholecytectomy. ${ }^{1} 1112$ There is no role for piece meal excision in surgical management.

There are a few reported cases using single chemotherapy regimen as adjuvant therapy. ${ }^{11}$ However, these adjuvant chemotherapies have not seen adding any remission benefit or survival benefit. 5-Fu is a main chemotherapy regimen in treating gallbladder carcinoma and oxaliplatin (a third-generation platinum analog) is used in treating sarcomas such as soft tissue sarcoma and gynaecological sarcoma. 5-Fu and oxaliplatin combination has been shown a significant survival benefit in treating aggressive colon cancers. ${ }^{28}$ In this case study, we first report using these two chemotherapy regimens as adjuvant chemotherapy in treating gallbladder carcinosarcoma. We believe that our case and management plan will provide a unique experience in treating gallbladder carcinosarcoma.

\section{Learning points}

- Gallbladder carcinosarcoma is a rare gastrointestinal malignancy with poor prognosis.

- Patient suffering gallbladder carcinosarcoma usually present the symptoms of biliary tract obstruction and mass.

- Morphological and immunohistochemical studies are crucial in diagnosis of gallbladder carcinosarcoma.

- Currently, we still do not have standardised management for gallbladder carcinosarcoma; however, this case report provides a unique experience in treating this kind of patients.

\section{Competing interests None.}

Patient consent Obtained.

\section{REFERENCES}

1. Huguet KL, Hughes CB, Hewitt WR. Gallbladder carcinosarcoma: a case report and literature review. J Gastrointest Surg 2005;9:818-21.
2. Chan KM, Yeh TS, Yu MC, et al. Gallbladder carcinoma with biliary invasion: clinical analysis of the differences from nonbiliary invasion. World J Surg 2005;29:72-5.

3. Takahashi Y, Fukushima J, Fukusato T, et al. Sarcomatoid carcinoma with components of small cell carcinoma and undifferentiated carcinoma of the gallbladder. Pathol Int 2004;54:866-71.

4. Sodergren MH, Silva MA, Read-Jones SL, et al. Carcinosarcoma of the biliary tract: two case reports and a review of the literature. Eur $J$ Gastroenterol Hepatol 2005;17:683-5.

5. Iezzoni JC, Mills SE. Sarcomatoid carcinomas (carcinosarcomas) of the gastrointestinal tract: a review. Semin Diagn Pathol 1993;10:176-87.

6. Ajiki T, Nakamura T, Fujino Y, et al. Carcinosarcoma of the gallbladder with chondroid differentiation. J Gastroenterol 2002;37:966-71.

7. Chao TC, Wang CS, Jeng LB, et al. Primary carcinoma of the gallbladder in Taiwan. J Surg Oncol 1996;61:49-55.

8. Landsteiner K. Plattenepithelkarzinom und sarkom der gallenblase in cinem falle von cholelithiasis. Zischr Klin Med 1907:62:427-33.

9. Jiang $\mathbf{X}$, Zhang $X$, Li FY, et al. Gallbladder carcinosarcoma clinical and pathology observation. J Diagn Pathol 2005;12:178-80.

10. Ibrahim FS, Tariq J, Huttner I, et al. Carcinosarcoma of the gallbladder: a case report and review of literature. J Gastroenterol 2002;8:22-4.

11. Liu KH, Yeh TS, Hwang TL, et al. Surgical management of gallbladder sarcomatoid carcinoma. World J Gastroenterol 2009;15:1876-9.

12. Okabayashi T, Sun ZL, Montgomey RA, et al. Surgical outcome of carcinosarcoma of the gall bladder: a review. World J Gastroenterol 2009;15:4877-82.

13. Okamura $\mathbf{Y}$, Ishigure $\mathrm{K}$, Ushikawa $\mathrm{T}$, et al. A long-term survival case of carcinosarcoma of the gallbladder with chondroid differentiation after surgical curative resection. Jap J Gastroent Surg 2006;39:1501-10.

14. Kernochan LE, Garcia RL. Carcinosarcomas (malignant mixed Müllerian tumor) of the uterus: advances in elucidation of biologic and clinical characteristics. J Natl Compr Canc Netw 2009;7:550-6.

15. Wu AW, Wang XD, Ji JF. Carcinosarcoma of gallbladder: a case report. Chin J Cancer Res 2005;17:301-4.

16. Uzun MA, Koksal N, Gunerhan Y, et al. Carcinosarcoma of the gallbladder: report of a case. Surg Today 2009;39:168-71.

17. American Joint Committee on Cancer. AJCC Cancer Staging Manual. Sixth edition. New York: Springer 2002:145-9.

18. Fong $\mathbf{Y}$, Jarnagin W, Blumgart LH. Gallbladder cancer: comparison of patients presenting initially for definitive operation with those presenting after prior noncurative intervention. Ann Surg 2000;232:557-69.

19. Lumsden AB, Mitchell WE, Vohman MD. Carcinosarcoma of the gallbladder. a case report with immunohistochemical and ultrastructural studies. Cancer 1990;66:992-7.

20. Fagot $\mathbf{H}$, Fabre JM, Ramos J, et al. Carcinosarcoma of the gallbladder. A case report and review of the literature. J Clin Gastroenterol 1994; 18:314-16 


\section{BMJ Case Reports}

21. Kim MJ, Yu E, Ro JY. Sarcomatoid carcinoma of the gallbladder with a rhabdoid tumor component. Arch Pathol Lab Med 2003;127:e406-8.

22. Nakagawa T, Yamakado K, Takeda K, et al. An ossifying carcinosarcoma of the gallbladder: radiologic findings. AJR Am J Roentgenol 1996;166:1233-4.

23. Born MW, Ramey WG, Ryan SF, et al. Carcinosarcoma and carcinoma of the gallbladder. Cancer 1984;53:2171-7.

24. Kadono J, Hamada N, Higashi M, et al. Carcinosarcoma of the extrahepatic bile duct. J Hepatobiliary Pancreat Surg 2005;12:328-31.

25. Katsuhiko U, Nimura Y, Hayakawa N, et al. Carcinosarcoma of the gallbladder: a case report and review of the literature. $J$ Hepatobiliary Pancreat Surg 1995;2:446-50.
26. Yoo HJ, Yun BR, Kwon JH, et al. Genetic and expression alterations in association with the sarcomatous change of cholangiocarcinoma cells. Exp Mol Med 2009;41:102-15

27. Kuroki T, Tajima Y, Matsuo K, et al. Genetic alterations in gallbladder carcinoma. Surg Today 2005;35:101-5.

28. André T, Boni C, Mounedji-Boudiaf L, et al. Oxaliplatin, fluorouracil, and leucovorin as adjuvant treatment for colon cancer. N Engl J Med 2004;350:2343-51.

This pdf has been created automatically from the final edited text and images.

Copyright 2011 BMJ Publishing Group. All rights reserved. For permission to reuse any of this content visit http://group.bmj.com/group/rights-licensing/permissions.

BMJ Case Report Fellows may re-use this article for personal use and teaching without any further permission.

Please cite this article as follows (you will need to access the article online to obtain the date of publication).

Pu JJ, Wu W. Gallbladder carcinosarcoma. BMJ Case Reports 2011;10.1136/bcr.05.2010.3009, date of publication

Become a Fellow of BMJ Case Reports today and you can:

- Submit as many cases as you like

- Enjoy fast sympathetic peer review and rapid publication of accepted articles

Access all the published articles

- Re-use any of the published material for personal use and teaching without further permission

For information on Institutional Fellowships contact consortiasales@bmjgroup.com

Visit casereports.bmj.com for more articles like this and to become a Fellow 